\title{
Isolation and characterization of a Bacillus subtilis strain that degrades endosulfan and endosulfan sulfate
}

\author{
Ajit Kumar • Narain Bhoot . \\ I. Soni · P. J. John
}

Received: 24 February 2013/Accepted: 19 September 2013/Published online: 1 October 2013

(C) The Author(s) 2013. This article is published with open access at Springerlink.com

\begin{abstract}
Endosulfan has emerged as a major environmental menace worldwide due to extensive usage and environmental persistence, seeking its remedial by a cheaper and efficient means. Therefore, natural resource (soil) was explored to search a potential candidate for biodegradation of endosulfan. A soil bacterium was enriched and isolated by applying a strong nutritional selection pressure, using a non-sulfur medium supplemented with endosulfan as sole source sulfur. The microbial strain was found to degrade endosulfan as well as its equally toxic metabolite endosulfan sulfate to non-toxic metabolites (endodiol and endosulfan lactone) very efficiently (up to $94.2 \%$ ) within 7 days, estimated qualitatively by thin layer chromatography and quantitatively by gas chromatography-electron capture detection methods. The isolate was characterized for its morphological, physiological, biochemical and 16S rRNA sequencing and identified as a new strain of Bacillus subtilis with strain designation AKPJ04, which was deposited with accession number Microbial Type Culture Collection and Gene Bank
\end{abstract}

Genbank submission: The 16S rDNA sequence of Bacillus subtilis AKPJ04 was deposited in GenBank database under accession number EU 258611.

Electronic supplementary material The online version of this article (doi:10.1007/s13205-013-0176-7) contains supplementary material, which is available to authorized users.

A. Kumar · N. Bhoot · I. Soni · P. J. John

Environment Toxicology Unit, Centre for Advanced Studies in

Zoology, University of Rajasthan, Jaipur 302004, India

Present Address:

A. Kumar $(\bowtie)$

Centre for Bioinformatics, M.D. University,

Rohtak 124001, India

e-mail: akumar.cbt.mdu@gmail.com
(MTCC) 8561, at MTCC, Institute of Microbial Technology, Chandigarh, India. The partial 16S rRNA sequence was submitted to Genbank, Maryland, USA, with the accession number EU 258611. The primary investigation for endosulfan degrading gene(s) localization suggested its location on chromosomal DNA.

Keywords Biodegradation - Endosulfan - Bacillus subtilis $\cdot$ Characterization

\section{Introduction}

With the advent of Green Revolution, use of synthetic fertilizers and pesticides has increased at an uncontrolled pace to meet the demands of ever-growing human population. To the darker side of the same, these compounds, particularly, pesticides have posed a serious ecological threat and therefore needs an early scientific attention. Presently, endosulfan is one of the extensively used organochlorine pesticides after the worldwide ban on DDT and BHC. Since then, use of endosulfan has increased dramatically in last three decades. It is used extensively worldwide as a contact and stomach insecticide for Colorado potato beetle, flea beetle, cabbageworm, peach tree borer, tarnished plant bug and as an acaricide on field crop like cotton, paddy, sorghum, oilseeds and coffee (Lee et al. 1995; Kullman and Matsumura 1996; USEPA 2002), apart from its use in vector-control (tsetse fly), as a wood preservative and for the control of home garden pests (C.N.R.C 1975). It is a highly toxic substance and is classified as a Category $1 \mathrm{~b}$ (highly hazardous) pesticide by USEPA (2002).

There have been several reports of acute poisoning and chronic toxicity of endosulfan. Acute toxicity includes 
stimulation of Central Nervous System as the major characteristic and is indistinguishable from symptoms of other cyclodienes (USDHHS 1990). Endosulfan has been reported to be highly toxic to aquatic fauna like fish and invertebrates (Sunderam et al. 1992). In addition, there are reported implications in mammalian gonadal toxicity (Sinha et al. 1997), genotoxicity (Chaudhari et al. 1999), teratogenic effects (Yadav 2003) and mutagenic effects (USDHHS 1990). These acute and chronic toxicity and environmental concerns have attracted scientists for an effective and economically viable option search for endosulfan degradation.

Bioremediation has evolved as a very economical and viable process for detoxification of xenobiotics in general and pesticides in particular, as an alternative to existing methods such as incineration and landfill (Gavrilescu and Chisti 2005). Therefore, present investigations were carried out in our laboratory to enrich and isolate endosulfan degrading microorganism from the natural resource (soil), having the past history of endosulfan usage. The isolated strains were studied for their comparative pesticide degradation ability to select the best biodegrader. The best degrading isolate $\mathrm{N} 2$ was found to degrade both the isomers of endosulfan ( $\alpha$ - and $\beta$-isomers) along with the equally toxic metabolite endosulfan sulfate up to $94 \%$ within 7 days (Kumar et al. 2012).

The present report describes the biochemical and molecular characterization and identification of the best endosulfan degrading isolate N2 and comparative analysis of its degradation profile with the standard microorganisms (MOs) reported earlier for endosulfan degradation, Phanerochaete chrysosporium (Kullman and Matsumura 1996) and Mucor thermohyalospora (Shetty et al. 2000).

\section{Materials and methods}

Technical grade endosulfan (99\% pure), an organochlorine insecticide with the chemical name 6,7,8,9,10,10hexachloro-1,5,5a,6,9,9a-hexahydro-6,9-methano-2,4,3benzo-dioxathiepin-3-oxide for the study, was gifted by Excel India Pvt. Ltd., Ahmedabad, India (Fig. 1). The endosulfan isomers ( $\alpha$ - and $\beta$-isomers), endosulfan sulfate and other endosulfan metabolite standards for chromatographic analyses were purchased from Hewlett Packard Company, Wilmington, Delaware, USA. Chloroform, $n$-hexane and acetone of chromatographic grade were used for chromatographic studies. All other chemicals used for the study were of analytical grade. The earlier reported endosulfan degraders, P. chrysosporium MTCC 4955 (PC) and M. thermohyalospora MTCC 1384 (MT), were selected as standards for the comparative study and were purchased from Microbial Type Culture Collection and Gene Bank
(MTCC), Institute of Microbial Technology (IMTECH), Chandigarh.

Culturing of isolate N2 and standard MOs

The isolate $\mathrm{N} 2$ for the study of endosulfan degradation profile was cultured in non-sulfur medium (NSM) supplemented with 50-ppm technical endosulfan as sole source of sulfur (Table 1). The other culture conditions included $\mathrm{pH} 6.5$ with rotational agitation of $130 \mathrm{rpm}$, and incubation temperature and time of $30^{\circ} \mathrm{C}$ and 15 days, respectively. The culture conditions were as per optimized parameters reported earlier, with little modification (Kumar et al. 2012). The other two MOs, PC and MT, were cultured as per their corresponding reports (Kullman and Matsumura 1996; Shetty et al. 2000) for comparative study of endosulfan degradation.

Analysis of endosulfan degradation and characterization of metabolites

For endosulfan and its metabolites extraction and analysis, $5 \mathrm{ml}$ of cultured broth of the isolate N2, PC and MT were subjected with equal volumes of ethyl acetate and the organic phase was passed through a 6-cm $\mathrm{MgSO}_{4}$ column in a Pasteur pipette to remove any residual water. The columns were prewashed with ethyl acetate. The extracted elutes containing pesticide and metabolites were gently evaporated at $50{ }^{\circ} \mathrm{C}$ in oven and were dissolved in acetone (chromatographic grade) and stored in glass vial at $4{ }^{\circ} \mathrm{C}$ for further analysis. A fortification test for recovery of endosulfan isomers was carried out for further chromatographic analysis.

The sample extracts of the N2-culture medium were analyzed for the residues of endosulfan by Gas Chromatography-Electron Capture Detection (GC-ECD) method. The analysis was carried out on a Shimadzu Model 2010 Gas chromatograph (GC) equipped with 63Ni Electron capture detector (ECD), and a capillary column HP ultra 2 (US 4293415) $0.52 \times 25 \times 0.32$. The instrument was supported by Lab Solutions software for the analysis of endosulfan ( $\alpha$ - and $\beta$-isomers) and endosulfan sulfate. The stock standards (200-ppm) of endosulfan isomers and endosulfan sulfate were obtained from Hewlett Packard Company, USA. Stock standards of 100 -ppm were prepared by diluting standard mixture in 1:1 solvent mixture of HPLC grade iso-octane and toluene. These stocks were stored under freezing conditions. Working standard of the mixture was prepared from 100-ppm stock solution. $0.5-1.0 \mathrm{ppm}$ of this mixture of endosulfan isomers and endosulfan sulfate was used for calibrating the GC for analyzing residues of endosulfan in the sample analyzed.

For thin layer chromatography (TLC), the dried endosulfan isomers and metabolites, after extraction from the culture, were dissolved in chromatographic grade acetone and applied to 
Fig. 1 Endosulfan and its isomers (technical grade composition- $\alpha: \beta:: 7: 3)$<smiles></smiles>

Endosulfan

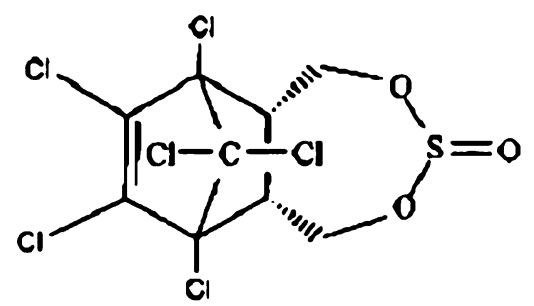

Endosulfan (alpha isomer)

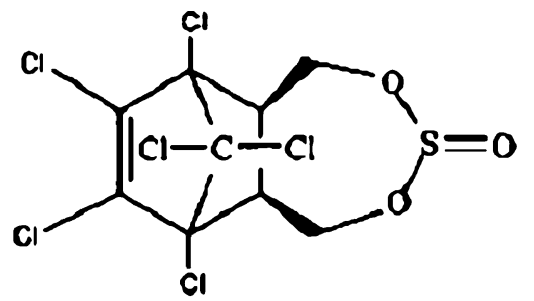

Endosulfan (beta isomer)
Table 1 Composition of (a) non-sulfur medium (NSM) $(\mathrm{pH}=6.5$ ), (b) Trace elements solution

\begin{tabular}{cll}
\hline S. no. & Chemical & Amount (g/liter) \\
\hline a & & \\
1 & $\mathrm{~K}_{2} \mathrm{HPO}_{4}$ & 0.225 \\
2 & $\mathrm{KH}_{2} \mathrm{PO}_{4}$ & 0.225 \\
3 & $\mathrm{NH}_{4} \mathrm{Cl}$ & 0.225 \\
4 & $\mathrm{MgCl}_{2} \cdot 6 \mathrm{H}_{2} \mathrm{O}$ & 0.845 \\
5 & $\mathrm{CaCO}_{3}$ & 0.005 \\
6 & $\mathrm{FeCl}_{2} \cdot 4 \mathrm{H}_{2} \mathrm{O}$ & 0.005 \\
7 & $\mathrm{D}-\mathrm{Glucose}$ & 1.000 \\
8 & $\mathrm{Trace} \mathrm{element} \mathrm{solution}$ & $1 \mathrm{mg} / \mathrm{lt}$ \\
$\mathrm{b}$ & & \\
1 & $\mathrm{MnCl}_{2} \cdot 4 \mathrm{H}_{2} \mathrm{O}$ & 198 \\
2 & $\mathrm{ZnCl}_{2}$ & 136 \\
3 & $\mathrm{CuCl}_{2} \cdot 2 \mathrm{H}_{2} \mathrm{O}$ & 171 \\
4 & $\mathrm{CoCl}_{2} \cdot 6 \mathrm{H}_{2} \mathrm{O}$ & 24 \\
5 & $\mathrm{NiCl}_{2} \cdot 6 \mathrm{H}_{2} \mathrm{O}$ & 24 \\
\hline
\end{tabular}

neutral Silica gel TLC plates (pre-activated at $80{ }^{\circ} \mathrm{C}$ for $30 \mathrm{~min}$ ). The plates were developed in hexane: chloroform: acetone (9:3:1). The chlorine-containing constituents were visualized by spraying plates with $\mathrm{AgNO}_{3}$-saturated methanol and then exposing them to UV-light (Kovacs 1965).

\section{Characterization and identification of isolate N2}

The isolate N2 was subjected to different morphological characterizations (colony morphology, negative staining, gram staining and endospore staining) along with different biochemical characterizations (Cappuccino and Sherman 2005). A growth curve was plotted using NSM with endosulfan as sole source of sulfur for isolate N2 under optimized culture conditions. Its growth was monitored for a temperature range of $15-50{ }^{\circ} \mathrm{C}$, a $\mathrm{pH}$ range of 4.0-9.0 and salinity range of $2.0 \% \mathrm{NaCl}-10.0 \% \mathrm{NaCl}$ concentrations for further physiological characterization.

The partial 16S rRNA gene sequencing of isolate N2 was carried out by the custom services of IMTECH, Chandigarh, India, and was subjected to sequence homology search using BLAST (Altshcul et al. 1990) to identify the isolate. The phylogenetic analysis of the isolate N2 was also carried out using CLUSTAL-W (Larkin et al. 2007) for multiple sequence alignment, and a phylogenetic tree was constructed using Neighbour-Joining method of Phylip version 3.69 (Felsenstein 2005).

Primary localization of endosulfan degrading gene in isolate $\mathrm{N} 2$

The isolate N2 was also looked for plasmid content by attempting plasmid isolation by alkaline lysis method (Sambrook et al. 1989) and boiling lysozyme preparation method (Ausubel et al. 2005). E. coli DH5 $\alpha$ (plasmid strain) was run as positive control in both the plasmid isolation protocol and $1.0 \%$ agarose gel was run for visualization of DNA bands.

\section{Results and discussion}

Fortification test for endosulfan recovery from microbial cultures

The fortification tests for recovery of endosulfan isomers from microbial cultures during degradation analysis were 
conducted for five concentrations $(0.5,5.0,10,50$ and $100 \mathrm{ppm}$ ) of endosulfan in the culture broth. The recovery was observed to range from 92.5 to $102.8 \%$ for $\alpha$-endosulfan and 93.2 to $104.1 \%$ for $\beta$-endosulfan with the coefficient of variation ranging from 0.8 to $2.8 \%$ and 0.84 to $4.2 \%$ for $\alpha$-endosulfan and $\beta$-endosulfan, respectively. Based on the fortification analysis of recovery experiments for both endosulfan isomers, the extractions were considered appropriate of residue analysis.

GC-ECD \& TLC analysis of endosulfan degradation profile

After GC-separation and ECD analysis, it was found that $8.65 \mathrm{ppm}$ of $\alpha$-endosulfan, $5.85 \mathrm{ppm}$ of $\beta$-endosulfan and $2.98 \mathrm{ppm}$ of endosulfan sulfate remained in the N2-culture system, accounting for about $71.0 \%$ degradation after 3 days of incubation, as compared to $24.82 \mathrm{ppm}$ of $\alpha$ endosulfan, $15.81 \mathrm{ppm}$ of $\beta$-endosulfan and $6.42 \mathrm{ppm}$ of endosulfan sulfate detected in the control sample accounting for $18.74 \%$ abiological degradation. After 7 days of incubation, the degradation of endosulfan in N2culture system was found to be $94.0 \%$ with $1.79 \mathrm{ppm}$ of $\alpha$ endosulfan, $1.21 \mathrm{ppm}$ of $\beta$-endosulfan and $0.32 \mathrm{ppm}$ of endosulfan sulfate detected by GC-ECD as compared to $23.93 \mathrm{ppm}$ of $\alpha$-endosulfan, $14.78 \mathrm{ppm}$ of $\beta$-endosulfan and $6.98 \mathrm{ppm}$ of endosulfan sulfate detected in the control sample that accounts for $22.58 \%$ abiological degradation (Table 2).

Isolate $\mathrm{N} 2$ was also investigated for its comparative degradation with positive control cultures of reported standard microbes, namely, Phanerochaete chrysosporium (Kullman and Matsumura 1996) and Mucor thermohyalospora MTCC 1384 (Shetty et al. 2000). This comparison was made on the basis of analyzing endosulfan degradation and its metabolites' profile recovered from the respective culture media after 15 days of incubation, under respective standard culture conditions. The TLC-plate analysis revealed six spots, identified as $\alpha$-endosulfan, $\beta$-endosulfan, endosulfan sulfate, endosulfan lactone, endosulfan hydroxyether and endosulfan diol, on the basis of their respective retention factor $\left(R_{\mathrm{f}}\right)$ of $0.69,0.46,0.36,0.29$, 0.21 and 0.10 . Endosulfan sulfate was the only abiotic degradation metabolite observed in the control, while cultures of N2, PC and MT showed endosulfan diol and endosulfan sulfate as the two common metabolites. Endosulfan diol was produced maximum in the cultures of N2, while PC and MT produced the same as minor metabolite. A spot of endosulfan lactone was observed in the cultures of N2, while no such spot was observed for PC and MT. A spot of endosulfan hydroxyether was observed only for PCculture while no such metabolite was detected in N2 and MT (Table 3).

The major metabolite detected in the isolate $\mathrm{N} 2$ was endosulfan diol with little amount of endosulfan lactone. Endosulfan hydroxyether was not detected in the isolate similar to M. thermohyalospora MTCC 1384 and in contrast to $P$. chrysosporium. In $P$. chrysosporium, endosulfan diol and endosulfan hydroxyether were detected, while no trace of endosulfan lactone was observed. M. thermohyalospora MTCC 1384 had endosulfan diol as the only metabolite detected apart from spots of $\alpha$-endosulfan, $\beta$ endosulfan and endosulfan sulfate, observed commonly in all the samples. These observations were in accordance with their respective reported findings (Kullman and Matsumura 1996; Shetty et al. 2000). Shetty et al. (2000) reported about degradation of endosulfan by $M$. thermohyalospora to form endosulfan diol as the major

Table 2 Gas chromatography-ECD data of endosulfan isomers and endosulfan sulfate after degradation by isolate N2

\begin{tabular}{|c|c|c|c|c|c|}
\hline Sample & Peak\# & Retention time (min) & Compound & $\begin{array}{l}\text { Concentration } \\
(\mathrm{ppm})\end{array}$ & $\begin{array}{l}\text { Endosulfan } \\
\text { degradation }(\%)\end{array}$ \\
\hline \multirow[t]{3}{*}{ Control (Day 3) } & 24 & 13.818 & $\alpha$-Endosulfan & 24.82 & \multirow[t]{3}{*}{18.74} \\
\hline & 32 & 15.751 & $\beta$-Endosulfan & 15.81 & \\
\hline & 37 & 17.207 & Endosulfan sulfate & 6.42 & \\
\hline \multirow[t]{3}{*}{ Control (Day 7) } & 25 & 13.800 & $\alpha$-Endosulfan & 23.93 & \multirow[t]{3}{*}{22.58} \\
\hline & 32 & 15.729 & $\beta$-Endosulfan & 14.78 & \\
\hline & 37 & 17.205 & Endosulfan sulfate & 6.98 & \\
\hline \multirow[t]{3}{*}{ N2 (Day 3) } & 26 & 13.757 & $\alpha$-Endosulfan & 8.65 & \multirow[t]{3}{*}{71.0} \\
\hline & 32 & 15.708 & $\beta$-Endosulfan & 5.85 & \\
\hline & 38 & 17.207 & Endosulfan sulfate & 2.98 & \\
\hline \multirow[t]{3}{*}{ N2 (Day 7) } & 27 & 13.709 & $\alpha$-Endosulfan & 1.79 & \multirow[t]{3}{*}{94.0} \\
\hline & 32 & 15.697 & $\beta$-Endosulfan & 1.21 & \\
\hline & 33 & 17.207 & Endosulfan sulfate & 0.32 & \\
\hline
\end{tabular}

Culture condition: Media, NSM with 50-ppm technical endosulfan as sole source of sulfur; $\mathrm{pH}, 6.5$; Temperature, $30^{\circ} \mathrm{C}$; Agitation, $130 \mathrm{rpm}$ 
Table 3 TLC profile of endosulfan degradation by isolate N2 and standard cultures of P. chrysoporium (PC) and M. thermohyalospora (MT)

\begin{tabular}{|c|c|c|c|c|c|}
\hline Metabolites & Rf Value ${ }^{\S}$ & Control* & $\mathrm{N} 2 *$ & $\mathrm{PC}$ & MT \\
\hline$\alpha$-Endosulfan & 0.69 & +++ & + & + & + \\
\hline$\beta$-Endosulfan & 0.46 & + & + & + & + \\
\hline Endosulfan sulfate & 0.36 & + & + & + & + \\
\hline Endosulfan lactone & 0.29 & - & + & - & - \\
\hline Endosulfan hydroxyether & 0.21 & - & - & + & - \\
\hline Endosulfan diol & 0.10 & - & +++ & + & + \\
\hline
\end{tabular}

Culture condition: Media, NSM with 50-ppm technical endosulfan as sole source of sulfur; $\mathrm{pH}, 6.5$; Temperature, $30{ }^{\circ} \mathrm{C}$; Agitation, $130 \mathrm{rpm} ;+++$, Formation of major metabolite; + , formation of minor metabolites, - , no metabolite detected

$\S$ TLC solvent system used: hexane:petroleum ether:acetone (9:3:1)

metabolite. Kullman and Matsumura (1996) found that $P$. chrysosporium degraded endosulfan in endosulfan diol and endosulfan hydroxyether by utilizing both oxidative and hydrolytic pathways for metabolism of this pesticide.

\section{Morphological characterization of isolate N2}

The isolate N2 was found to be Gram +ve, long, rodshaped bacilli after gram staining and negative staining. It was also found to be a spore former after performing endospore staining with subterminally/centrally positioned, ellipsoidal and no-swollen spores. Isolate N2 was found to form elevated, large, round and convex colonies with shiny mucoid surface as observed from its colony morphology. The size of the bacterium was found to be $2-4 \mu$ in length and $<1.0 \mu$ in width. The bacteria were observed to be arranged in singles and pairs.

\section{Physiological characterization}

The isolate $\mathrm{N} 2$ was observed to grow in the temperature range of $20-50{ }^{\circ} \mathrm{C}$, while no growth was observed at a temperature of $15{ }^{\circ} \mathrm{C}$ (Table 4). Growth of the bacterium was found to occur in the $\mathrm{pH}$ range of 6.0-9.0 and a salinity range of $2.0-10.0 \% \mathrm{NaCl}$ (Table 4).

The growth curve of N2 was found to be a normal sigmoidal with a delayed lag phase of about $30 \mathrm{~h}$. The log phase was found to extend up to $84 \mathrm{~h}$ after which the culture showed stationary phase up to $192 \mathrm{~h}$ (8 days). The decline phase initiated after $192 \mathrm{~h}$ as evident from growth curve (Fig. 2).

\section{Biochemical characterization}

The isolated bacterium tested positive for citrate utilization, TSI test (acid form glucose), Casein hydrolysis, Esculin hydrolysis, Gelatin hydrolysis, Starch hydrolysis, Nitrate hydrolysis, Catalase test, Lysine decarboxylase test and ortho-nitrophenyl glucuronide (ONPG) test. The
Table 4 Physiological characterizations of isolate N2

\begin{tabular}{lc}
\hline Tests* & Results \\
\hline Growth at temperatures ${ }^{\#}$ & \\
$15{ }^{\circ} \mathrm{C}$ & - \\
$20{ }^{\circ} \mathrm{C}$ & + \\
$30{ }^{\circ} \mathrm{C}$ & + \\
$37{ }^{\circ} \mathrm{C}$ & + \\
$42{ }^{\circ} \mathrm{C}$ & + \\
$50{ }^{\circ} \mathrm{C}$ & + \\
$(\# \mathrm{pH} 6.5, \mathrm{NaCl} \mathrm{2 \% )}$ & \\
$\mathrm{Growth}$ at $\mathrm{pH}$ & \\
4.0 & - \\
6.0 & + \\
7.0 & + \\
8.0 & + \\
9.0 & + \\
Growth on $\mathrm{NaCl}(\%)$ & + \\
2.0 & + \\
5.0 & + \\
7.0 & + \\
10.0 & + \\
\hline
\end{tabular}

- , No growth; +, Growth

* All tests were conducted in nutrient medium

results were negative for growth on MacConkey agar, Indole test, Methyl red test, Voges-Proskauer tests, $\mathrm{H}_{2} \mathrm{~S}$ production, gas from glucase, TSI test (acid from lactose), Urea hydrolysis, Arginine dihydrolase, Ornithine decarboxylase and Phosphatase test.

\section{Molecular characterization}

The partial nucleotide base sequencing (1,396 base pairs) of 16S rRNA gene of isolate N2 was done to identify the bacterium. After performing BLAST search for sequence homology at GenBank, the bacteria showed $100 \%$ identity with Brevibacterium halotolerans strain DSM 8802, 
Bacillus subtilis subsp. subtilis strain DSM 10, Bacillus vallismortis strain DSM11031, Bacillus mojavensis strain IFO15718, Bacillus amyloliquefaciens strain NBRC 15535 and $99 \%$ identity with $B$. subtilis subsp. Spizizenii strain NRRL B-23049 with $100 \%$ query coverage of $16 \mathrm{~S}$ ribosomal RNA gene. Multiple sequence alignment using CLUSTAL-W was performed for the top scoring sequences of BLAST results showing $95 \%$ and above maximum indent with the query coverage of $97 \%$. The phylogenetic tree was obtained using .phy output file of CLUSTAL-W with the help of NJ-method of Phylip (Fig. 3).

On the basis of above characterizations, the isolate was identified as a new strain of $B$. subtilis and was deposited at MTCC, IMTECH, Chandigarh, as strain designation

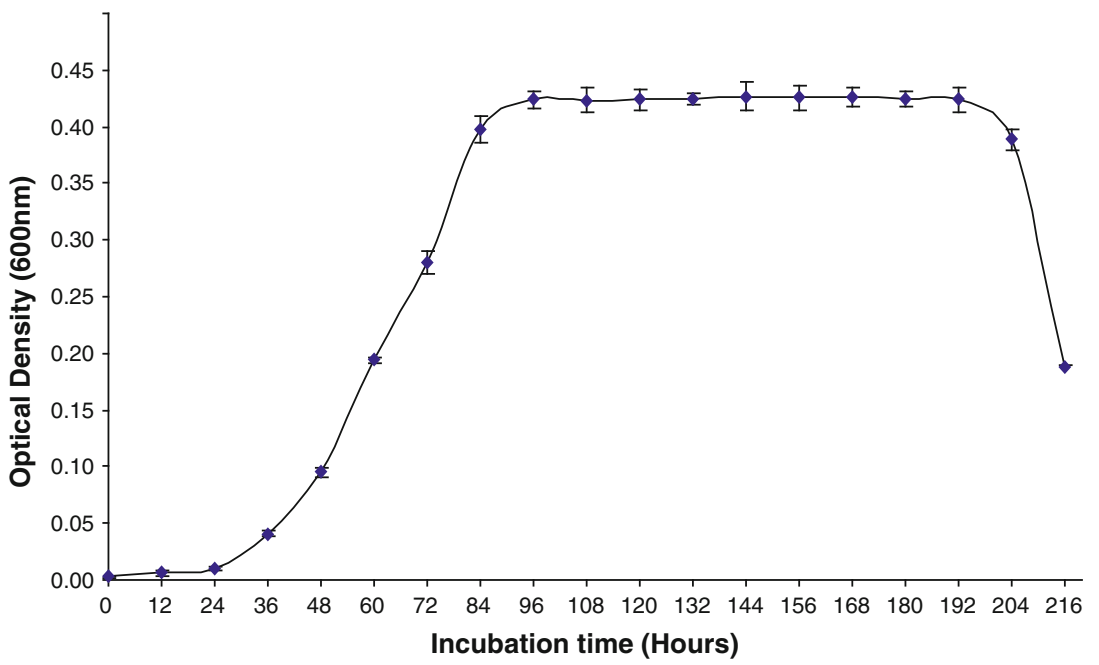

Fig. 2 Growth curve of isolate N2. The values are the mean of triplicate samples, and the bar indicates the standard error. The culture conditions include the NSM media with 50-ppm technical endosulfan as sole source of sulfur, $\mathrm{pH} 6.5$, incubation temperature of $30{ }^{\circ} \mathrm{C}$ and rotator agitation of $130 \mathrm{rpm}$

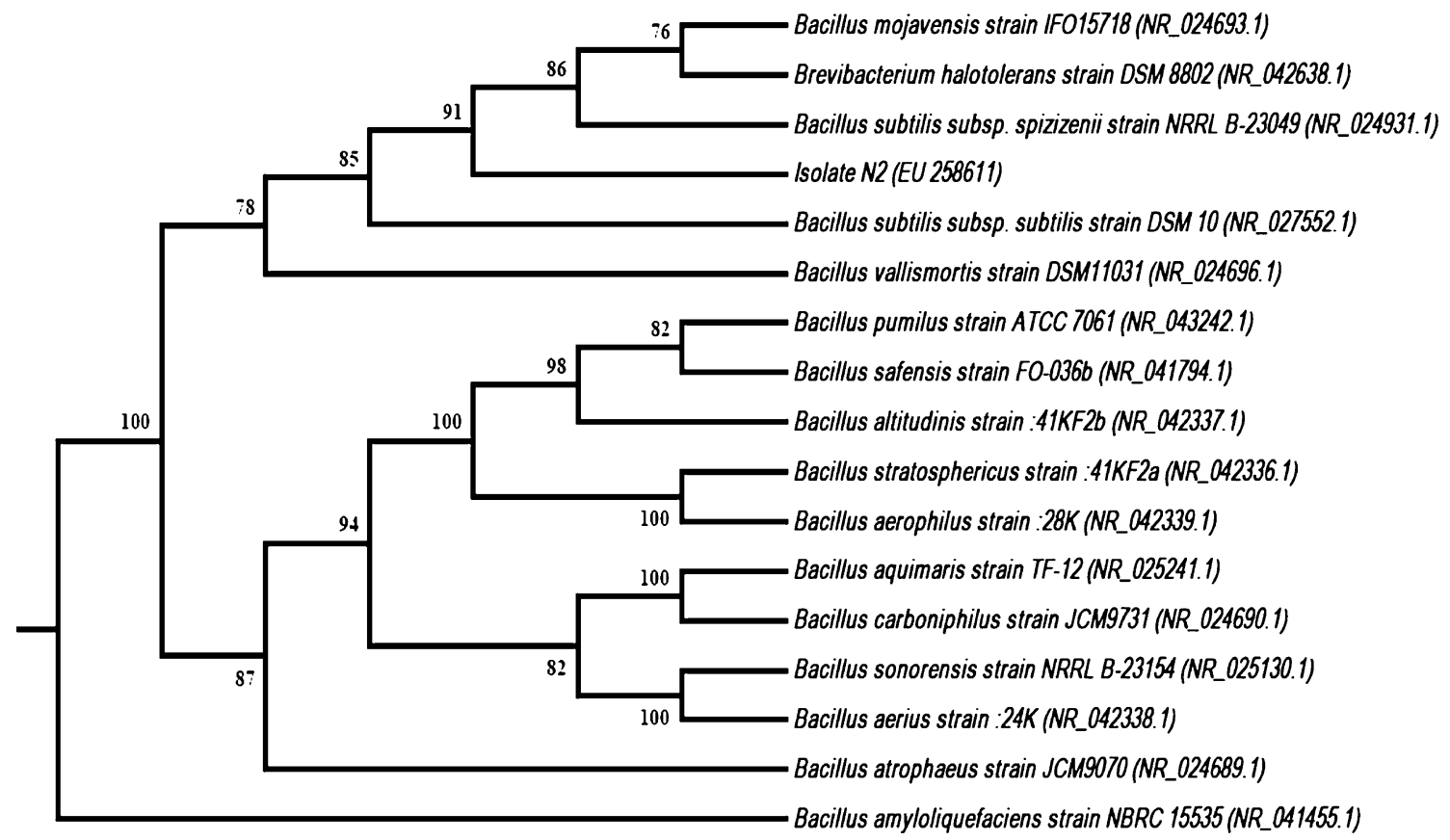

Fig. 3 Phylogenetic analysis of isolate N2. The tree is based on 16S rRNA gene sequences from top scoring homologous strains of Bacillus and closely related genera. GenBank accession numbers are indicated in the parenthesis. B. Amyloliquefaciens strains NBRC
15535 was used as the outgroup. Bootstrap values $>70 \%$ are given. The scale used for the distance-based tree was 0.01 substitutions per nucleotide position 
AKPJ04 and accession number MTCC 8561, while the 16S rRNA gene sequence of the same was deposited and later published at Genbank with the accession number EU 258611.

The bacterial genus Bacillus has also been reported earlier to have endosulfan degradation ability. A bacterial co-culture consisting of two Bacillus sp. (MTCC 4444 and MTCC 4445) has been reported to degrade and reduce the toxicity of endosulfan, utilizing the pesticide as carbon source (Awasthi et al. 1997, 2003). The present isolate, $B$. subtilis MTCC 8561, is probably the first Bacillus sp. to be reported till date which can utilize endosulfan as sulfur source (Kataoka and Takagi 2013) and degrade it very efficiently up to $94 \%$. Other bacterial system reported to degrade endosulfan using it as sulfur source are Alcaligenes faecalis strain JBW4 (Kong et al. 2013), Pseudomonas fluorescens (Giri and Rai 2012), Achromobacter xylosoxidans strain C8B (Singh and Singh 2011), Pseudomonas and Burkholderia (Hussain et al. 2007), Arthrobacter (Weir et al. 2006), Pandoraea (Siddique et al. 2003), Mycobacterium (Sutherland et al. 2000) and Micrococcus (Guha et al. 1999). Degradation of endosulfan by bacterial consortia isolated from contaminated soil has also been recently reported (Bhattacharjee et al. 2013).

Primary localization of endosulfan degrading gene(s) of isolate N2

When plasmid isolation from the isolate $\mathrm{N} 2$ was attempted by alkaline lysis method, a smear of RNA was obtained when observed under UV-light after agarose gel electrophoresis, while the positive control (E. coli DH5 $\alpha$ ) showed two discrete plasmid bands of closed circular plasmid and nicked plasmids (Fig. 4a). While attempting plasmid isolation, using lysozyme-heat shock treatment method, a smear of RNA was obtained $\left(\mathrm{N} 2{ }^{\$}\right.$ lane of Figs. 4b). No band was observed under UV-light when the isolated nucleic acid was treated with RNase and electrophoretic run (Lane $\mathrm{N} 2^{\#}$ of Fig. 4b). It may therefore be inferred that isolate $\mathrm{N} 2$ does not harbor any plasmid, as there were negative results of plasmid isolation against the positive control. The isolate $\mathrm{N} 2$ ( $B$. subtilis) was found to be devoid of any plasmid. The plasmid extraction was carried out by alkaline lysis prep method and confirmed by lysozyme boiling-miniprep method. This observation suggests that the endosulfan degrading gene(s) is located on chromosomal DNA. This finding is in accordance with the reports about chromosome-located esd-gene of Mycobacterium (Sutherland et al. 2002) and ese-gene of Arthrobacter (Weir et al. 2006), which have been shown responsible for endosulfan degradation.

\section{Conclusion}

The findings of present investigations suggest that the isolate is probably the first Bacillus sp. reported till date, to use endosulfan as sulfur source and the extent of biodegradation of the pesticide is also very high as compared to other reported microbes. The major metabolite detected after degradation by the said isolate

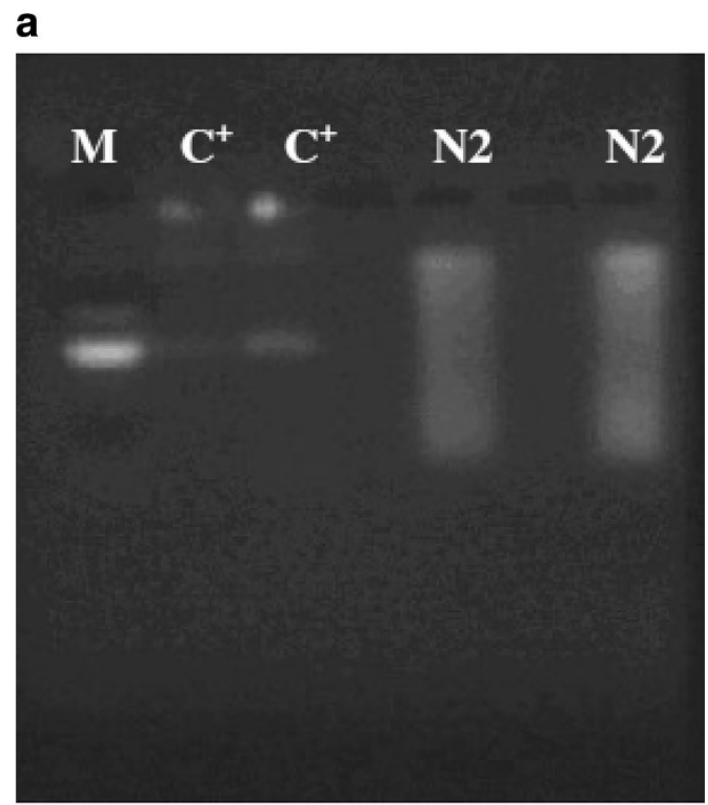

b

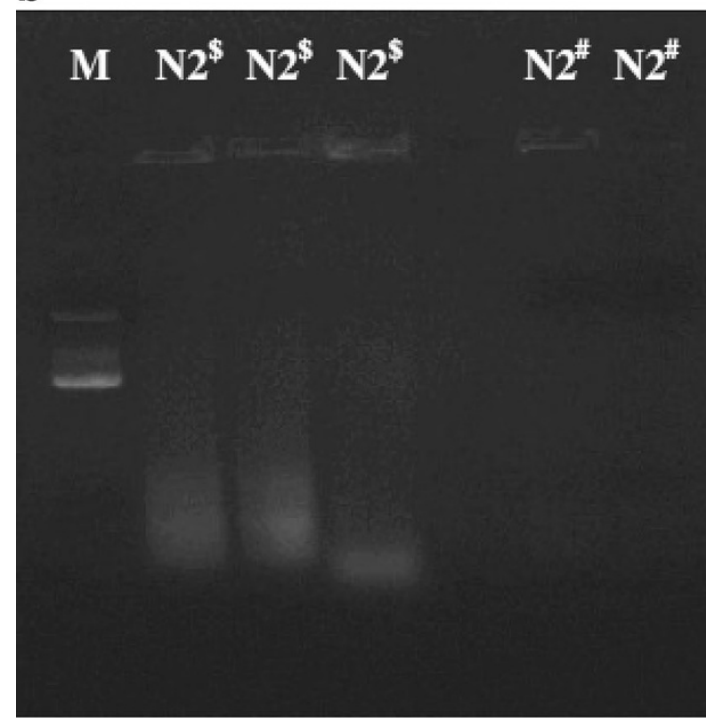

Fig. 4 a Plasmid isolation from isolate N2. Agarose gel showing plasmid isolation results of isolate $\mathrm{N} 2$ by alkaline lysis method. $[M$ marker lane, $C+$ positive control lane $(E$. coli $\mathrm{DH} 5 \alpha), N 2$ isolate N2 lane]. b Plasmid isolation from isolate N2. Agarose gel showing plasmid isolation results of isolate $\mathrm{N} 2$ by lysozyme treatment method. ( $M$ Marker lane, $N 2^{\$}$ isolate $\mathrm{N} 2$ lane without RNase treatment, $N 2^{\#}$ isolate N2 lane after RNase treatment) 


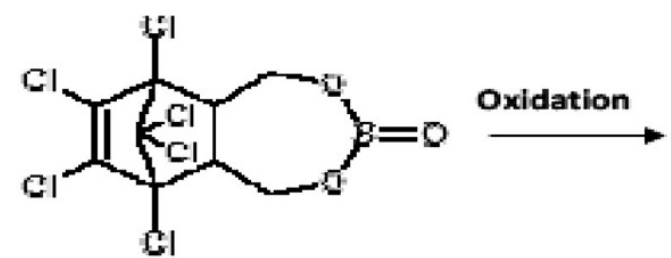<smiles>O=C1OCC2C3(CO1)COC(=O)C(Cl)(Cl)C1(Cl)C(Cl)(C(Cl)=C(Cl)C21Cl)C3Cl</smiles>

Endosulfan

Endosulfate

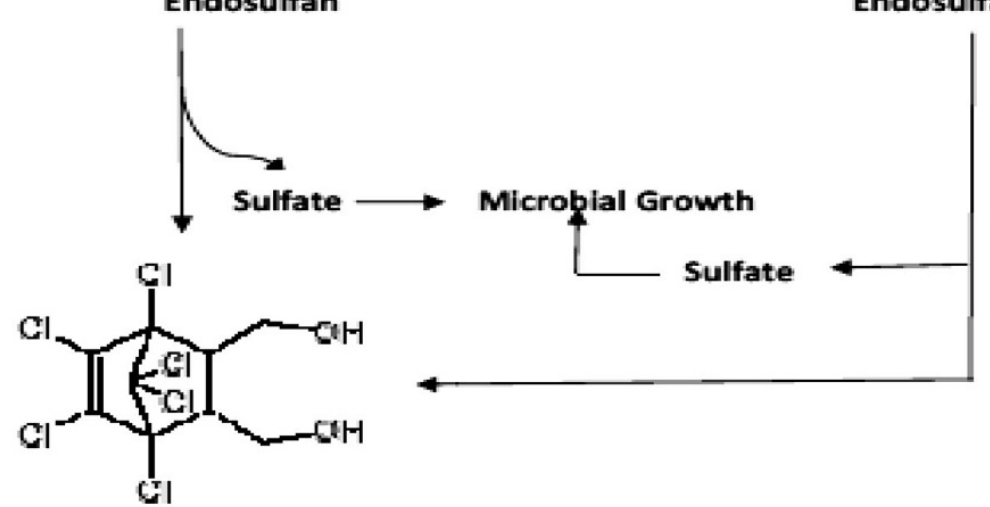

Endosulfan diol

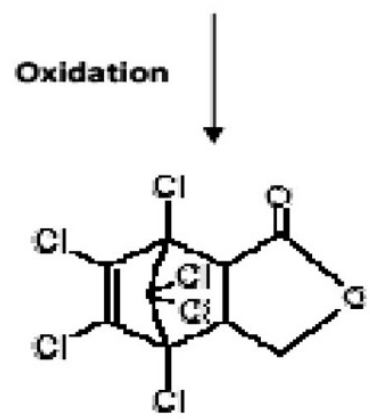

Endosulfan lactone

Fig. 5 Proposed pathway for metabolism of endosulfan by Bacillus subtilis MTCC 8561

(B. subtilis) is endosulfan diol along with endosulfan lactone and endosulfan sulfate detected as minor products. From the metabolites detected after degradation, it has been inferred that the bacterium metabolizes endosulfan and its stable but equally toxic, oxidized product, endosulfan sulfate by directly hydrolyzing it to endosulfan diol followed by oxidation to form endosulfan lactone. The high amount of endosulfan diol, detected after bacterial degradation of the pesticide, suggests that the bacterium is hydrolyzing the compounds to release sulfite group from endosulfan and sulfate group from endosulfan sulfate for using them as sulfur source in metabolism and growth. The proposed degradation pathway of endosulfan by B. subtilis AKPJ04 is as represented in Fig. 5. Both the major metabolites produced are non-toxic in nature and thus, the isolate holds promise to be a very good candidate for bioremediation of endosulfan. The present study paves a good platform for scaling and validating the results from shake flask level to soil study. The present work also beckons for the identification and characterization of the gene(s) and enzymes, responsible for endosulfan degradation, that are presently under our investigation.

Acknowledgments The authors wish to thank FASC, MITS, Lakshmangarh, Sikar, Rajasthan, India, for providing laboratory facilities for carrying out the present investigation and IMTECH, Chandigarh, India, for providing facility for $16 \mathrm{~S}$ rRNA sequencing.

Conflict of interest The authors declare no financial or commercial conflict of interest.

Open Access This article is distributed under the terms of the Creative Commons Attribution License which permits any use, distribution, and reproduction in any medium, provided the original author(s) and the source are credited. 


\section{References}

Altshcul SF, Gish W, Miller W, Myers EW, Lipman DJ (1990) Basic local alignment search tool. J Mol Biol 215:403-410. (http:// www.ncbi.nlm.nih.gov/BLAST/)

Ausubel FM, Brent R, Kingston RE, Moore DD, Seidman JG, Smith JA, Struhl K (eds) (2005) Short protocols in molecular biology: a compendium of methods from current protocols in molecular biology. John Wiley \& Sons, New York

Awasthi N, Manickam N, Kumar A (1997) Biodegradation of endosulfan by a bacterial co-culture. Bull Eviron Contam Toxicol 59:928-934

Awasthi N, Singh AK, Jain RK, Khangarot BS, Kumar A (2003) Degradation and detoxification of endosulfan isomers by a defined co-culture of two Bacillus strains. Appl Microbiol Biotechnol 62:279-283

Bhattacharjee K, Banerjee S, Bawitlung L, Krishnappa D, Joshi SR (2013) A study on parameters optimization for degradation of endosulfan by bacterial consortia isolated from contaminated soil. Proc Natl Acad Sci India Sect B Biol Sci. doi:10.1007/ s40011-013-0223-5

Cappuccino JG, Sherman N (2005) Microbiology A laboratory manual. In: 6th edn. Pearson Education Pvt. Ltd., Delhi

Chaudhari K, Selvaraj S, Pal AK (1999) Studies on the genotoxicity of endosulfan in bacterial system. Mutat Res 439:63-67

C.N.R.C. (1975) Endosulfan: its effects on environmental quality. In: NRC Associate committee on scientific criteria for environmental quality, Canada National Research (CNRC), Report No. 11, Subcommittee of pesticides on related compounds, Subcommitte Report No. 3, Publication No. NRCC 14098 of the Environmental Secretariat

Felsenstein J (2005) PHYLIP: (Phylogeny inference package) version 3.6. (http://evolution.genetics.washington.edu/phylip.html)

Gavrilescu M, Chisti Y (2005) Biotechnology- a sustainable alternative for chemical industry. Biotechnol Adv 23:3339-3348

Giri K, Rai JPN (2012) Biodegradation of endosulfan isomers in broth culture and soil microcosm by Pseudomonas fluorescens isolated from soil. Int J Environ Stud 69(5):729-742

Guha A, Kumari B, Bora TC, Roy MK (1999) Degradation of endosulfan by Micrococcus sp. and partial characterization of metabolites. Asian J Microbiol Biotech Environ Sci 1:29-32

Hussain S, Arshad M, Saleem M, Zahir ZA (2007) Biodegradation of $\alpha-$ and $\beta$-endosulfan by soil bacteria. Biodegradation 18(6):731-740

Kataoka R, Takagi K (2013) Biodegradability and biodegradation pathways of endosulfan and endosulfan sulphate. Appl Microbiol Biotechnol 97:3285-3292

Kong L, Zhu S, Zhu L, Xie H, Wei K, Yan T, Wang J, Wang J, Wang F, Sun F (2013) Colonization of Alcaligenes faecalis strain JBW4 in natural soils and its detoxification of endosulfan. Appl Microbiol Biotechnol

Kovacs MF (1965) Thin layer chromatography for pesticide residue analysis. J Assoc Off Agric Chem 97:982-988
Kullman SW, Matsumura F (1996) Metabolic pathways utilized by Phanerochaete chrysosporium for degradation of the cyclodiene pesticide endosulfan. Appl Environ Microbiol 62:593-600

Kumar A, John PJ, Soni I (2012) Enrichment and isolation of endosulfan degrading microorganism from natural resource. J Bio Environ Sci 2(6):41-53

Larkin MA, Blackshields G, Brown NP, Chenna R, McGettigan PA, McWilliam H, Valentin F, Wallace IM, Wilm A, Lopez R, Thompson JD, Gibson TJ, Higgins DG (2007) ClustalW and ClustalX version 2. Bioinformatics 23(21):2947-2948. (http:// www.ebi.ac.uk/clustalW/)

Lee N, Sherrit JH, Mc Adam DP (1995) Hapten synthesis and development of ELISAs for the detection of endosulfan in water and soil. J Agric Food Chem 43:1730-1739

Sambrook J, Fritsch EF, Maniatis T (1989) Molecular cloning: a laboratory manual, 2nd edn. Cold Spring Harbor Laboratory Press, New York

Shetty PK, Mitra J, Murthy NBK, Namitha KK, Savitha KN, Raghu K (2000) Biodegradation of cyclodiene insecticide endosulfan by Mucor thermohyalospora MTCC 1384. Curr Sci 79:1381-1383

Siddique T, Okeke BC, Arshad M, Frankenberger WT Jr (2003) Enrichment and isolation of endosulfan-degrading microorganisms. J Environ Qual 32:47-54

Singh NS, Singh DK (2011) Biodegradation of endosulfan and endosulfan sulphate by Achromobacter xylosoxidans strain C8B in broth medium. Biodegradation 22:845-857

Sinha N, Narayan R, Saxena DK (1997) Effect of endosulfan on testis of growing rats. Bull Environ Contam Toxicol 58:79-86

Sunderam RIM, Cheng DMH, Thompson GB (1992) Toxicity of endosulfan to native and introduced fish in Australia. Environ Toxicol Chem 11:1469-1476

Sutherland TD, Horne I, Harcourt RL, Russell RJ, Oakeshott JG (2000) Enrichment of an endosulfan-degrading mixed bacterial culture. Appl Environ Microbiol 66:2822-2828

Sutherland TD, Weir KM, Lacey MJ, Horne I, Russell RJ, Oakeshott JG (2002) Enrichment of a microbial culture capable of degrading endosulfate, the toxic metabolite of endosulfan. J Appl Microbiol 92:541-548

USDHHS-United States Department of Health and Human Services (1990) Toxicological profile for endosulfan. Agency for Toxic Substances and Disease Registry, Atlanta

USEPA (2002) Re-registration eligibility decision (RED) fact sheet. United States Environmental Protection Agency (USEPA), EPA738-F-02-012 for Endosulfan (Case 0014)

Weir KM, Sutherland TD, Horne I, Russell RJ, Oakeshott JG (2006) A single monooxygenase, Ese, is involved in the metabolism of organochlorides endosulfan and endosulfate in an Arthrobacter sp. Appl Environ Microbiol 72:3524-3530

Genbank: http://www.ncbi.nlm.nih.gov/Web/Genbank/

Yadav KPS (2003) Weight lent to endosulfan study discarded by officials. Down Earth 12:7 